\title{
Assessment the Effectiveness of Preparedness for Relative Constant Factors in Environmental Disaster Management: A Case Study from Riyadh City, Saudi Arabia
}

\author{
Al Garni A. Mohammad1*, Awadelkarim M. Ali2, Alhijan A. Ahmad ${ }^{3}$ \\ ${ }^{1}$ Institute of Environmental Studies, University of Khartoum, Khartoum, Sudan \\ ${ }^{2}$ Faculty of Medicine, University of Khartoum, Khartoum, Sudan \\ ${ }^{3}$ The Shora Council, Riyadh, Kingdom of Saudi Arabia \\ Email: *al-garni@gmail.com
}

Received 30 March 2016; accepted 20 May 2016; published 23 May 2016

Copyright @ 2016 by authors and Scientific Research Publishing Inc.

This work is licensed under the Creative Commons Attribution International License (CC BY). http://creativecommons.org/licenses/by/4.0/

(c) (i) Open Access

\section{Abstract}

The preparedness phase is considered as backbone of environmental disaster management. The aim of this study is to identify the effect of relatively constant factors of preparedness phase on environmental disaster management in Riyadh City, Saudi Arabia. The study used descriptive and analytical approach besides the comprehensive survey depends upon questionnaire for purposive data surveyed all employees in the field of environmental disaster management in Riyadh city including administrations, department, and contains 21 sector including public and private sector for total population of about 397 persons and sample size about 353 persons using statistical tests, frequencies, percentage, average, standard deviation and $t$ test and $\times$ square test as well as Likert procedure on which depends on the measurement such as: very high, high, average, weak and very weak. The main results reveal that the constant factors of environmental disaster management are more important for evaluating the preparedness phase. Since the relatively constant factors of environmental disaster management are more important. The study recommends that: 1) Enhancement of the systems and procedures in particular disaster management procedures. 2) It is so necessary to publish a new unit for disaster management in the sectors have not. 3) Increase and encouragement of environmental disaster management studies in particular for preparedness phase because it considers as backbone of disaster management and suggestion of regional and local organizations link generally and in information trade off and the details studies in particular by providing the different types of support and encouragement.

\footnotetext{
"Corresponding author.

How to cite this paper: Mohammad, A.G.A., Ali, A.M. and Ahmad, A.A. (2016) Assessment the Effectiveness of Preparedness for Relative Constant Factors in Environmental Disaster Management: A Case Study from Riyadh City, Saudi Arabia. Journal of Environmental Protection, 7, 926-933. http://dx.doi.org/10.4236/jep.2016.76082
} 


\section{Keywords}

\section{Preparedness, Environmental Disaster Management, Riyadh City}

\section{Introduction}

Environmental disaster management considers as apparentness of humanitarian treatment that faced the humanity along the era. Therefore, it does not consider an ad hoc and chaotic process but it became an organized administrative operation. On the basis of this, it depends on training and planning and aims into defining of causes of disaster, identifying the influential factors affected it using the available capabilities to combat and control besides forecasting. This will be followed by experiences and new skills enhance the ways and tools of control of environmental disaster in the future [1]-[5].

No doubt, the environmental disaster effects should extend to all society and it differs according to its type and the nature of previous preparedness (before, during and after). However, the risks of environmental disaster might cause an accident effect for human being because the human beings are so effective in the society and have a big role in the rate of economic growth for each country. In doing so, it is obligating provide more protection and hedging for them [6] [7].

Based on the above, the advanced countries were initiative by establishing federal administrative environmental disasters agents like: FEMA in United States of America in 1979 on which it considers as a first one on this side. This is followed by a lot of institutions and organizations such as; civil defense Bureau and other authorities in some less developing countries [8].

It is worthy to note that, large literature emphasized that the phases of environmental disaster are just in three models and the majority of them are applied in triple environmental disaster management model which represent in; the preparedness phase; facing and the reposition phase [9].

The current study hypothesizes that: 1) There is a positive relationship between preparedness of planning and environmental disaster management effectiveness; 2) Also the study assumes a positive relationship between legislations system allegation, database and effectiveness of environmental disaster management, respectively.

The preparedness is considered as backbone of environmental disaster management, because the most former studies are revealed that the main cause of the huge disaster effect is neglecting of preparedness. Therefore, this study concentrates on to what extent the relative constant factors on effectiveness on preparedness and environmental disaster management and attempts to measure the degree of relationship between the preparedness' factors which are mentioned before. In other words this study attempts to identify the effect of relative constant factors of preparedness phase on environmental disaster management in Riyadh City, Saudi Arabia.

\section{Research Methodology}

The study uses descriptive and analytical approach besides the comprehensive survey depends upon questionnaire for purposive data surveyed all employees in the field of environmental disaster management in Riyadh city including administrations, department, and contains 21 sector including public and private sector for total population of about 397 person and sample size about 353 person. However, it focuses on the relative constant factors as mentioned before and uses statistical methods like frequencies, percentage, average, standard deviation and $t$ test and $\times$ square test as well as Likert procedure on which depends on the measurement such as: very high, high, average, weak and very weak.

According to Likert procedure the relative constant elements can be measured in average as follows: First, the average ranged between 4.2 - 5.0 for higher degree. Second, the average ranged between $(3.4$ - 4.19) for high degree. Third, the average ranged between $(2.6$ - 3.39) for averaged degree. Fourth, the average ranged between ( 1 - 1.79) for very weak and lastly, the average ranged between 1.80 to 2.59 for weak degree. In the framework, the axes are classified into three categories according into the average value as following: from 3.5 to 5.0 for high level, from 2.5 to 3.5 for averaged level, and less than 2.5 for weaken level.

Also the questionnaire was divided into three axes included: 1) systematic registration axis (Sys.), 2) preparedness and ready of planning (Prep.), and 3) information and data base axis (Info.) as shown in (Figure 1). 


\section{Results}

We tried to identify and analyze the empirical findings and discuss the relationships, frequencies, percent, and sample size as ratio of total size..., etc. The data in Table 1 show the total size, sample size and percentage of the different studied institutions.

According to (Figure 2), the majority sample size their age ranged between 31 to 35 year and 40 to 45 year, and they account $20.1 \%$, while the age from 30 to 36 year are about $19.5 \%$, this followed by ranged age between

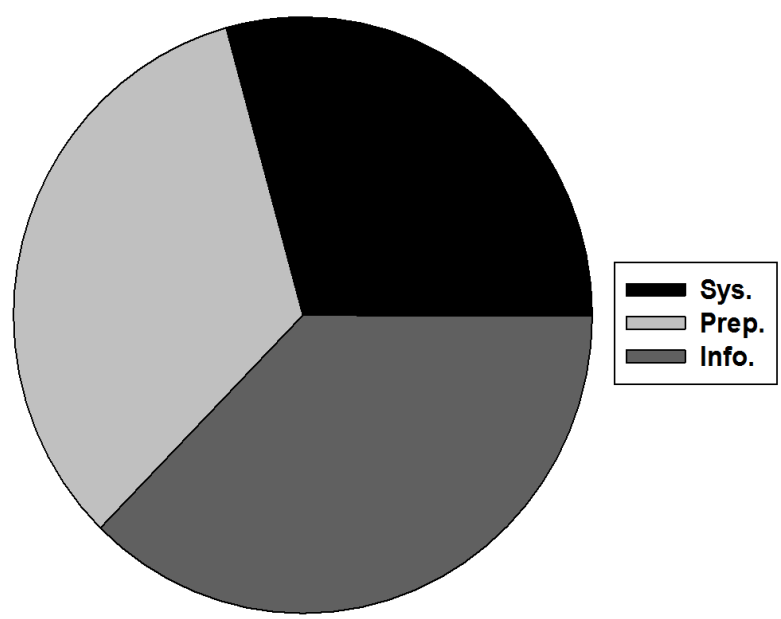

Figure 1. Distribution of words according to axes.

Table 1. Distribution of total size, sample size and the percentage.

\begin{tabular}{|c|c|c|c|}
\hline Institutions & Total size & Sample size & $\%$ \\
\hline The Civil Defense & 43.0 & 36.0 & 10.2 \\
\hline Ministry of Health & 30.0 & 26.0 & 7.40 \\
\hline Public Security & 35.0 & 26.0 & 7.40 \\
\hline Ministry of Water & 13.0 & 13.0 & 3.70 \\
\hline Board Guard & 19.0 & 15.0 & 4.20 \\
\hline SAPIC Company & 25.0 & 21.0 & 5.90 \\
\hline Red Crescent Corporation & 35.0 & 35.0 & 9.90 \\
\hline King Abdel Aziz for science and Technology & 11.0 & 9.00 & 2.50 \\
\hline Industrial Town Cities Corporation & 7.00 & 7.00 & 2.00 \\
\hline Metrology And Environment protection & 21.0 & 21.0 & 5.90 \\
\hline Ministry of Agriculture & 27.0 & 25.0 & 7.10 \\
\hline Ministry of Al-baladia & 18.0 & 17.0 & 4.80 \\
\hline King Corporation of Al Gebiel An Yenbu & 18.0 & 18.0 & 5.10 \\
\hline Railway Institution & 18.0 & 16.0 & 4.50 \\
\hline General Institution of Ports & 9.00 & 8.0 & 2.30 \\
\hline Ministry of Electricity & 27.0 & 21.0 & 5.90 \\
\hline Ministry of Transport & 17.0 & 15.0 & 4.20 \\
\hline Ministry of Trade and Industry & 7.00 & 7.00 & 2.00 \\
\hline Saudi Wald life & 5.00 & 5.00 & 1.40 \\
\hline Ministry of Culture and Information & 8.00 & 8.00 & 2.30 \\
\hline Ministry of petroleum & 4.00 & 4.00 & 1.10 \\
\hline Total & 397.0 & 353.0 & 100.0 \\
\hline
\end{tabular}




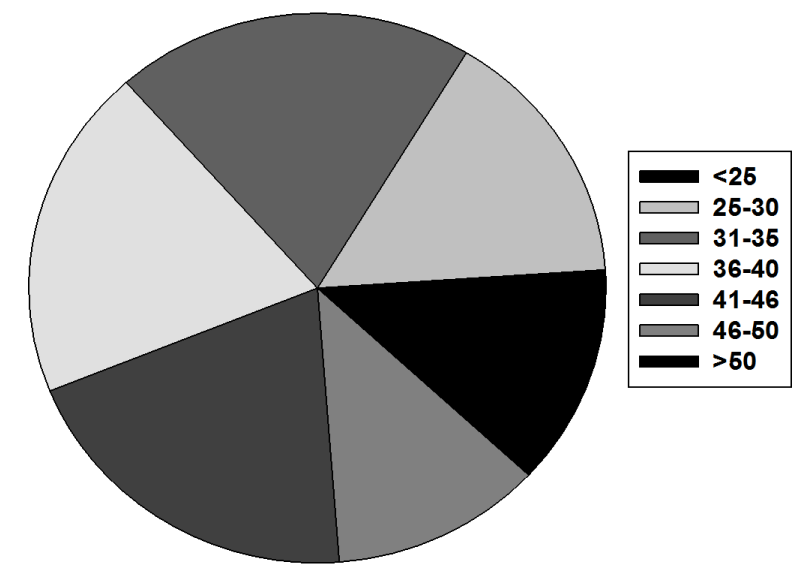

Figure 2. The frequency according to the age.

Table 2. Distribution of the sample size according to the institution of work.

\begin{tabular}{|c|c|c|}
\hline Institutions & NO. of frequency & $\%$ \\
\hline The Civil Defense & 36.0 & 10.2 \\
\hline Ministry of Health & 26.0 & 7.40 \\
\hline Public Security & 26.0 & 7.40 \\
\hline Ministry of Water & 13.0 & 3.70 \\
\hline Board Guard & 15.0 & 4.20 \\
\hline SAPIC Company & 21.0 & 5.90 \\
\hline Red Crescent Corporation & 35.0 & 9.90 \\
\hline King Abdel Aziz for science and Technology & 9.00 & 2.50 \\
\hline Industrial Town Cities Corporation & 7.00 & 2.00 \\
\hline Metrology And Environment protection & 21.0 & 5.90 \\
\hline Ministry of Agriculture & 25.0 & 7.10 \\
\hline Ministry of Al-baladia & 17.0 & 4.80 \\
\hline King Corporation of Al Gebiel An Yenbu & 18.0 & 5.10 \\
\hline Railway Institution & 16.0 & 4.50 \\
\hline General Institution of Ports & 8.00 & 2.30 \\
\hline Ministry of Electricity & 21.0 & 5.90 \\
\hline Ministry of Transport & 15.0 & 4.20 \\
\hline Ministry of Trade and Industry & 7.00 & 2.00 \\
\hline Saudi Wald life & 5.00 & 1.40 \\
\hline Ministry of Culture and Information & 8.00 & 2.30 \\
\hline Ministry of petroleum & 4.00 & 1.10 \\
\hline Total & 353.0 & 100.0 \\
\hline
\end{tabular}

25 to 30 year which are estimated at $15.3 \%$ following by 46 and less than 50 year and count $11.9 \%$. Based on the obtained findings, the majority of sample size in all sector of environmental disaster management is ranged between 31 to 45 year and account $60 \%$ from the total sample size.

The data in Table 2 clarify that the high percentage of sample are belong to the civil defense sector and count $10.20 \%$ followed by $9.90 \%$ in Saudi Red crescent and sectors of Ministry of health, general security by $7.40 \%$ respectively following by agricultural sector which represents 7.10\% and sectors of Metrology and environment protection, Yenbu and Gobail, SABIC company Saudi Railway, Baladia, Transportation, Board and Guard, Ministry of water, King Abdel Aziz City for Science and Technology (KACST), Ports and information, trade, 
industry and Saudi walled life are account 9.90\%, 7.4\%, 40\%, 7.10\%, 5.90\%, 5.10\%, 4.80\%, 4.50\%, 4.20\%, $3.70 \%, 2.50 \%, 2.30 \%, 2.0 \%, 1.40 \%$, and $1.10 \%$, respectively.

The distribution of Employee according to their jobs (Figure 3) indicates that the head department gob (H. D) accounts $33.10 \%$ which represents a high percentage on the sample size. This followed by the other jobs (other) by $25.20 \%$ and the head directors by $17.60 \%$, while the head department (H.D) and general managers (G.M) are represent $17.0 \%$ and $17.10 \%$, respectively. It is clear from Figure 4 according to qualification the bachelor degree (BS) represents a high percent by $57.20 \%$, however; the diploma (Dip.), master (MS) and high secondary degree (HS) are represent $20.10 \%, 13.0 \%$ and $6.50 \%$ respectively.

The data in Figure 5 explain that the high percentage of years of disaster experience are account about 27.70\% and ranged in 11 to 15 years old following by ages less than 5 years by about $22.50 \%$ and 5 to 10 years old, 6 to 20 years old, 21 to 25 years old, and 25 years and above by $19.60 \%, 16.40 \%, 8.40 \%$, and $5.50 \%$, respectively.

It is appears from Figure 6 that the distribution of sample according to the type of sector distributed as follows: the majority is account $88.10 \%$ are belong to government (Gov.) sector, whilst only 11.90 are belong into private sector (Priv.).

\section{Discussion}

This study raises some questions on three axes of systems and legislations, preparedness of planning and information database. These first hypotheses consist with systems axis and its appeared be volatile according to the respondent of sample size, which it indicates that the systems are distinctive by comprehensiveness in all sides

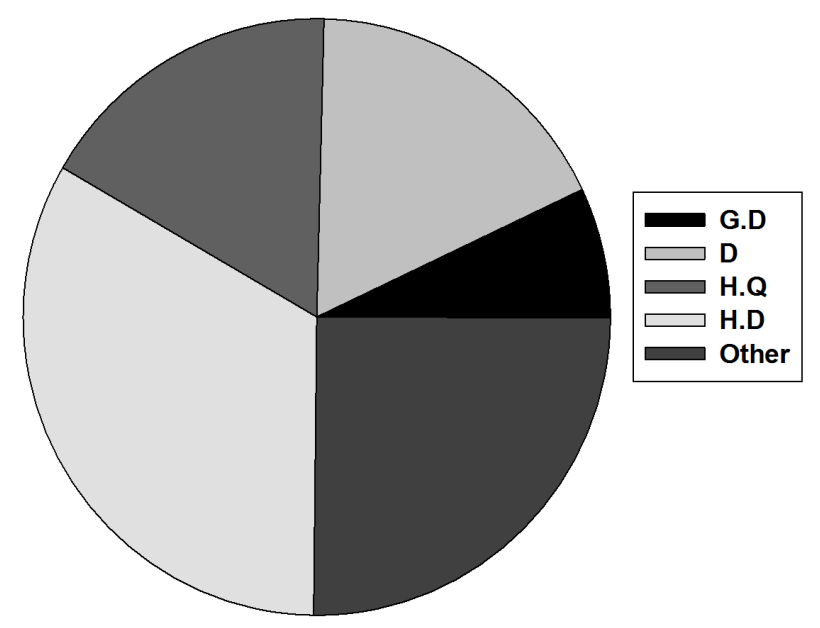

Figure 3. Distribution of employees according to Job.

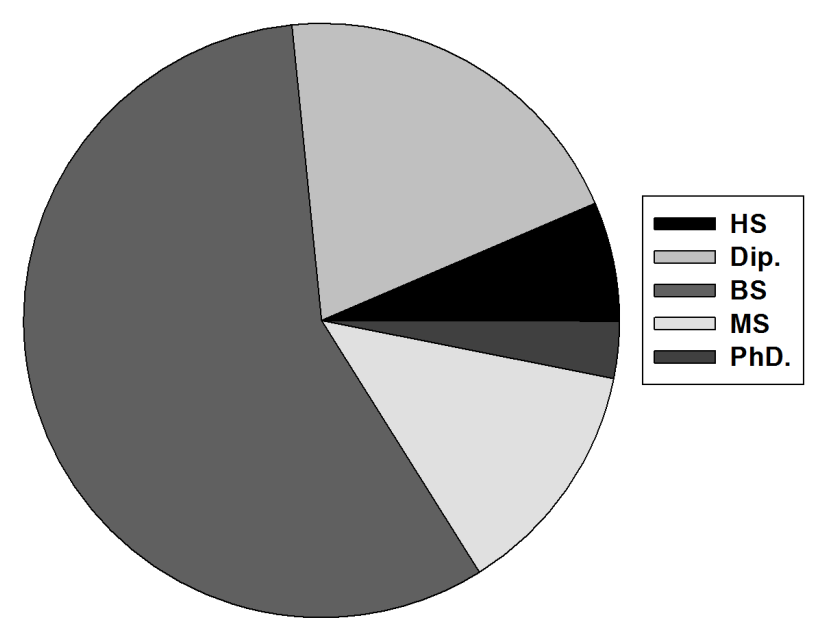

Figure 4. Distribution of employees according to qualification. 


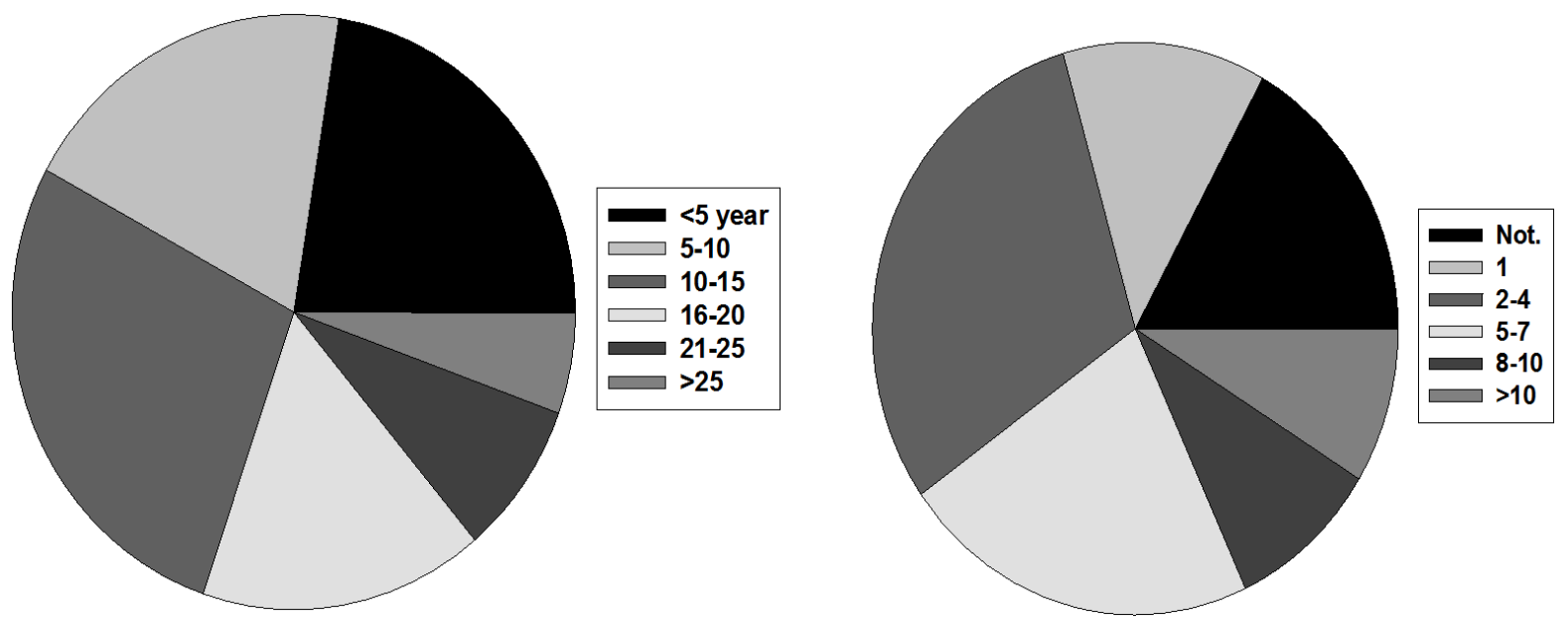

Figure 5. Distribution of employees according to years of disaster experience (a) and number of training courses in the environmental disaster management (b).

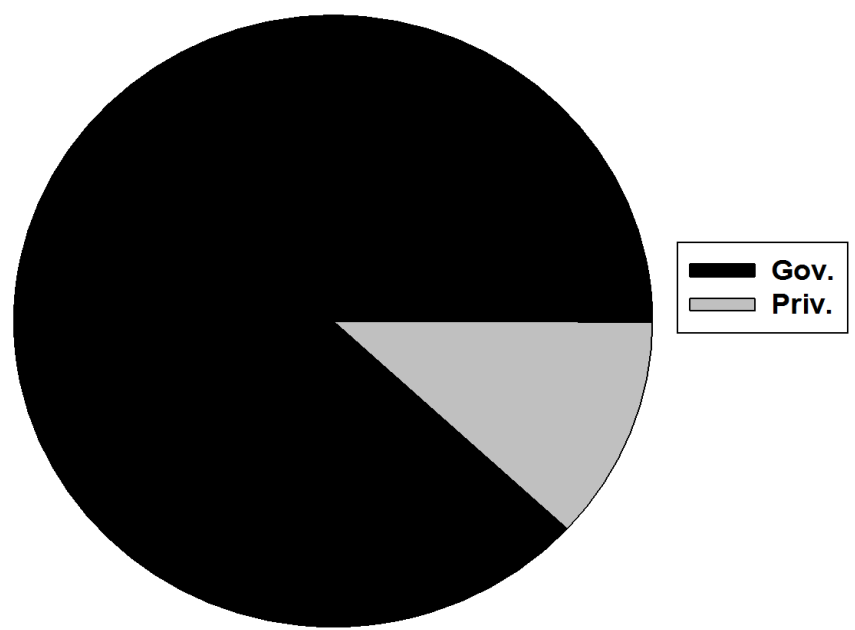

Figure 6. Distribution of employees according to type of sector.

by an average rate of 3.87 and standard deviation $( \pm \mathrm{SD}=0.86)$ and high and very high frequency account about $67.9 \%$ from the total population of size. The systems contribute on supporting the effort of mentioned sectors in reducing risks and it became in the second order by an average rate of 3.84 and standard deviation of $( \pm \mathrm{SD}=$ 0.91 ) and high frequency and very high frequency about $68.2 \%$. In the third order the systems became very clear by an average of 0.92 and frequency and high frequency accounted $68.5 \%$ by standard deviation of $( \pm \mathrm{SD}=3.81$ ), followed by the systems helps in reducing the loss by average of 3.36 and standard deviation of 0.94 and high degree of frequency ranged between high and very high accounted $65.4 \%$ from the total population. Therefore, the current systems are so adequate the purpose and become in order sixth by an average rate of 3.37 and standard distribution 0.86 and frequency ranged in high and very high degree by 45.3. In doing so, the fall down of systems fluctuated by an average rate of 2.72 and standard deviation of 0.96 and high and very high frequency accounted about $18.7 \%$. In light of all above, it is clear that the degree of preparedness is evaluated at high level and estimated at 3.45\%, therefore, Qai square test indicates significant relationship between environmental disaster management and systems and legislation. Hence, the answers of the respondents imply that the systems are comprehensive, clear, distinctive cycles, contributes into supporting the mentioned sector for reducing the risks and it's so adequate and sufficient where the tabulated q is 9.48. In the axis of preparedness of planning the results indicates that the general planning for facing disasters is good and it became at the first order by an average rate of 3.93 and standard deviation of 0.81 by frequency at high and very high level at $69.7 \%$. This followed by the clearance of planning and became at second order by an average rate of 3.83 and standard deviation of 0.85 
on which indicates that the tasks should be accurately determined by an avenge rate of 3.80 and standard deviation 0.88 with high frequency at $66.3 \%$. The detailed planning is good and became the fourth rank by average rate estimated at 3.72 and standard deviation of 0.85 with high frequency rate of $62.1 \%$. This is followed by the comprehensive and distinctive of planning with average rate of 3.55 and standard deviation 0.81 and frequency percent at $56.7 \%$. Also, result reveals that there are adequate specialized team workers for preparing and reviewing the planning by an average rate about 3.53 and standard deviation about 0.90 within frequency percent of $15 \%$ and it became at the sixth order. This indicates that the planning are descriptive by the reality at an average rate estimated at 3.48 and standard deviation of 0.85 with frequency rate of $50.5 \%$ besides the distinctive of planning by elasticity of 3.09 and standard deviation 0.84 by frequency percent of $30.6 \%$ on which the planning is occurred cyclically by an average rate of 2.98 and standard deviation of 0.90 by frequency rate of 27.5 . The finding emphasizes that the degree of preparedness is evaluated at high degree estimated at 3.55 with significant differences between the used planning and environmental disaster management according to $\times$ test. In doing so, there is significant difference between the detailed general planning; identified the tasks; clear and elastic planning's; reality of planning's; adequacy of labor teams; comprehensive planning; and environmental disaster management according to qui square which estimated at 9.48. Also, the main finding reveals that the information and database can be evaluated at an average rate at 2.97 with consistent of reality and qui square which indicates that there a significant relationship between the availability of data about different risks and between the availability of supporting sectors and availability of information about the volunteers on which the locations of risks information; planning of facing disasters; procedures of facing the disasters and comprehensiveness of database is adequate and available according tabulated qui square at 9.48. In light of the above the degree of systems and legislations evaluates at high level on which indicates that existence of systems and legislations' in different sectors in particular; civil defense system; meteorology systems; and more than 30 procedures for safety and environment protection. Also the study reveals that the sectors' preparedness is adequate and sufficient in case of emergency planning efficiency in addition to availability of data and information. Adding to this, planning preparedness as satisfactory on which it reveals the significant impact on the importance of identifying the objectives and tools as well as the role institutions participated organization on which it consists the good performance in adequate way.

\section{Recommendations}

Since the relatively constant factors of environmental disaster management are more important the study recommends by the following:

1) Enhancement of system and procedures in particular environmental disaster management procedures.

2) For the scarcity of specialized on disasters management, the government should support the specialized in this field.

3) It is so necessary to publish a new unit for environmental disaster management in the sectors have not.

4) Enhancement of data base axis by issuing center for database and link it by each sector because it's so important for predicting the future disasters.

5) Increase and encouragement of environmental disaster management studies in particular for preparedness phase because it considers as backbone of environmental disaster management.

6) Suggestion of regional and local organizations link generally and in information trade off and the details studies in particular by providing the different types of support and encouragement.

\section{References}

[1] Svinivas, H. and Nakagawa, Y. (2007) Environmental Implications for Disaster Preparedness: Lessons Learnt from the Indian Ocean Tsunami. Journal of Environmental Management, 89, 4-13. http://dx.doi.org/10.1016/j.jenvman.2007.01.054

[2] Al autaibi and Allah, A. (2006) The Role security field Roller in Disaster Management. Unpublished M.Sc., Nife University, Riyadh.

[3] Al Garni (2006) Principles of Disaster Management. Al-homiest Press, Riyadh.

[4] Armistrong, W. (2001) Engineering: Plastic Development Management, Holistic Approach. Cambridge University, London.

[5] Khaliel and Adas (1994) His Concept of His Tools and Methods. Majde Publishing Distribution, Amman, 173. 
[6] Al Saud, M. (2010) Risks Map of Dump in Jidda Town. Geographical Society, Periodical Series, King Saud University Press, Riyadh.

[7] Sena and Michael (2006) Disaster Event Ion and Preparedness. Lecture Notes, for Health Science Students, Ethiopia Public Health Training Initiative (EPHTI).

[8] Issues and Actins (2009) "Reducing Disaster Risk through Science”: The Full Report of the ISDR Scientific and Technical Committee (UN).

[9] Al hijan and Talib, B. (2014) The Evaluation of Civil Defense in King Areas for Disaster Management Phases; Disaster Management in King Saudi Arabia from Real Prospective for the period (18-19/10/1418). Public Management Institute, Riyadh. 